\title{
Analysis of the anti-cancer effect of ethyl-p-methoxycinnamate extracted cekur (Kaempferia galanga) on cancer cell lines with wild- type and null p53
}

\author{
Solachuddin Jauhari Arief Ichwan ${ }^{\S}$, Syahirah Sazelii, Widya Lestari ${ }^{1 *}$ \\ ${ }^{1}$ Department of Fundamental Dental and Medical Sciences, Kulliyyah of Dentistry, International \\ Islamic University Malaysia, 25200, Pahang, Malaysia \\ ${ }^{2}$ Faculty of Medicine, Universiti Kuala Lumpur (Royal College of Medicine Perak), Malaysia
}

\begin{abstract}
This study aimed to examine the in-vitro anti-cancer potential of ethyl-p-methoxycinnamate (EPMC), the major constituent of Kaempferia galanga ( $K$. galanga) in selected human lung adenocarcinoma cells line A549 (p53 wild-type) and H1299 (p53 null). The involvement of p53 pathway in the anti-cancer effect of EPMC on selected cells was determined using MTT assay and Real-time PCR. The MTT results show that EPMC induces cytotoxicity in a dosedependent manner in A549 cancer cell lines containing the p53 wild-type gene. Meanwhile, our RT-PCR results indicate that the apoptotic activity of EPMC does not involve the p53 pathway. Overall, these results indicate that EPMC compounds of $K$. galanga stimulates in vitro cytotoxic and apoptotic activity unrelated to the p53 pathway.
\end{abstract}

Keywords: Ethyl-P-Methoxycinnamate, Kaempferia Galanga, p53

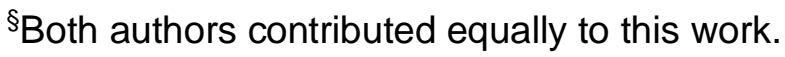

"Corresponding Author

Email address: drwidya@iium.edu.my

Tel: $+6019-9469755$

\section{Introduction}

Cancer is a major public health problem worldwide. There are many factors that may contribute to the development of cancer. In many cases, cancer involves mutations in protein-encoding genes that regulate cell division. Eventually, more genes become mutated because the genes that normally repair DNA damage become themselves mutated and cease to function. The amplification of mutations in the cell causes further abnormalities in the cell and its daughter cells.

TP53 (tumor suppressor gene p53) plays a significant role in protecting cells from malignancies. It is well-known that p53 suppresses tumor formation and protects against DNA damage by inducing cell cycle arrest, DNA repair or apoptosis (Wang and Sun, 2010). p53 induces cell cycle arrest by trans-activating genes such as p21 (CDK-inhibitor 1, cyclin dependent kinase) (Chiang et al., 2013). Furthermore, p53 initiates apoptosis via trans-activating pro-apoptotic proteins such as PUMA (p53 upregulated modulator of apoptosis) (Bai and Wang, 2014), BAX (Bcl-2-associated $X$ protein) or FAS (cell surface death receptor) (Wang and Sun, 2010).

However, the p53 is often mutated in cancer (Klein and Vassilev, 2004). 
Evidence suggests that, mutations or deletions in the TP53 gene are present in nearly $50 \%$ of human cancers and primarily results in impaired tumor suppression function (Wang et al., 2012). Loss of p53 functionality leads to the proliferation of damaged cells that may subsequently transfer the mutations to the next generation. It is believed that it is through this mechanism that deregulation of p53 often leads to the formation of tumors (Khoury and Domling, 2012).

Due to the high occurrence of $p 53$ mutations in human tumors, this tumor suppressor is a key target for novel anticancer therapies. Several research teams have dealt with the possibility of restoring p53 function to treat cancer. Many novel molecules have been identified so far to restore p53 wild-type conformation and thereby recover its tumor suppressive function (Hientz et al., 2017).

Thus far, a number of studies has reported that EPMC, a major constituent of volatile oil of $K$. galanga possesses in vitro anti-cancer activities on various cancer cell lines such as human colon cancer SW620, cervical cancer C33A, breast cancer MCF-7 cell lines and oral cancer HSC-3 and Ca922 cell lines (Amuamuta et al., 2017; Omar et al., 2017; Omar et al., 2016; Ichwan et al., 2019).

Despite these promising results, the question of the role of $K$. galanga in the p53 pathway remains unknown. Therefore, the objective of this study was to determine the in vitro anti-cancer potential of EPMC extracted from $K$.galanga against human cancer cell lines A549 (lung cancer, p53 wild-type) and H1299 (lung cancer, p53 null). The study also aims to explore the involvement of p53 pathway in anticancer mechanism of EPMC extract on human cancer cell lines.

\section{Materials and Methods}

\section{Cell subculturing and maintenance}

The human lung adenocarcinoma cells A549 (wild-type p53) and H1299 (null p53) were kindly provided by Prof. Dr. Masa Aki Ikeda, Tokyo Medical and Dental University, Japan. The cells were grown in Dulbecco's modified eagle medium (DMEM) supplemented with $10 \%$ fetal bovine serum (FBS) and 1\% PenicillinStreptomycin mixture in a humidified incubator, $5 \% \mathrm{CO}_{2}$ at $37^{\circ} \mathrm{C}$.

\section{MTT assay}

Cell viability was measured by the ability of the cells to convert soluble MTT into an insoluble formazan crystal. The assay was performed according to the protocol previously described (Ichwan et al., 2014) with slight modifications. Exponentially growing cells were subcultured in 96-well plates at an initial density of $2 \times 10^{4} /$ well. The cells were exposed to pre-defined concentrations of EPMC and doxorubicin for 24 hours.

After 24 hours of incubation, the medium was removed and the cells were washed with PBS. Cell viability was determined by adding $20 \mu \mathrm{L}$ MTT 3-(4, 5dimetyhlthiazol-2-yl)-2, 5-diphenyl tetrazolium bromide at a concentration of $5 \mathrm{mg} / \mathrm{ml}$ (in PBS). Cells were incubated at $37^{\circ} \mathrm{C}$ in humidified atmosphere for 4 hours. The formazan crystals were dissolved in $100 \mu \mathrm{L}$ of dimethylsulfoxide (DMSO) for 1 hour. The absorbance was measured in a spectrophotometer at a wavelength of $570 \mathrm{~nm}$ (reference: $630 \mathrm{~nm}$ ).

\section{Total RNA extraction}

The total RNA Mini Kit was acquired from Geneaid (Taiwan). RNA extraction was performed following the manufacturer's protocol. 


\section{Complementary DNA (cDNA) preparation}

cDNA synthesis was conducted using ReverTra Ace ${ }^{\circledR}$ qPCR RT Master Mix Kit (Toyobo, Japan) based on manufacturer's instructions. A total of $8 \mu$ of solution consisting of 4X DN Master Mix, RNA template, and nuclease-free water was prepared. After incubation for $5 \mathrm{~min}, 5 x$ Master Mix was added to the solution to a total of $10 \mu \mathrm{l}$ of reverse transcription solution. Then, the solution was incubated at $37^{\circ} \mathrm{C}$ for $15 \mathrm{~min}$ and heated at $98^{\circ} \mathrm{C}$ for 5 min to obtain cDNA.

\section{Quantitative PCR (qPCR)}

The mRNA expressions of p21 and PUMA were determined by qRT-PCR. The RTqPCR was performed using the Quantitect SYBR $^{\circledR}$ Green PCR (Qiagen) kit according to manufacturers's instructions. The qRTPCR reaction mixture consists of $2 x$ QuantiTect SYBR Green PCR master mix, pre-developed gene expression assays, primers mix and $\mathrm{H}_{2} \mathrm{O}$ to a final volume of $14 \mu \mathrm{L}$ were prepared. The relative expression level of the mRNA sample was normalized by the amount of $\beta$-actin, a housekeeping gene that was used as endogenous control.

\section{Statistical analysis}

Non-parametric Kruskal-wallis was used to test the significant difference of PUMA upregulation between doxorubicin and EPMC.

\section{Results and Discussion}

In brief, we used MTT assay to test whether EPMC induced cytotoxicity in human lung adenocarcinoma cell lines A549 (p53 wild-type) and H1299 (p53 null). The cells were exposed to graded concentrations of EPMC $(0-20 \mu \mathrm{g} / \mathrm{mL})$. EPMC was found to decrease cells viability in a dose-dependent manner in the presence of p53 (Figure 1). However, in the absence of p53, EPMC did not induce cytotoxicity and cell death (Figure 2).
The findings of this study would seem to suggest that presence of the p53 gene is a key factor for sensitivity to anticancer agents (El Deiry et al., 2003). The H1299 cell line has a recognized p53 gene deletion in both alleles. Thus, p53null cells succumb to tumorigenesis. Unlike p53-null, p53 wild-type have the ability to suppress malignant growth of transformed cells as well as tumors. Therefore, compounds that activate wildtype p53 would have an application for the treatment of wt-p53 containing human cancer. Nevertheless, mutated p53 confers to the resistance of tumor cells to anticancer drugs by inhibiting p53dependent pathway (Volgestein et al., 2000).

The cytotoxicity of EPMC on human lung cancer cell line was compared against doxorubicin, a wellknown chemotherapeutic agent as a positive control. EPMC and doxorubicin both induced the cytotoxic activity of p53 wild-type.

We next sought to determine whether EPMC was involved in the p53 pathway in $\mathrm{A} 549$ and $\mathrm{H} 1299$ cell lines through the expression of p53 mediated target genes (Beckerman et al., 2010). The p53 mediated target genes assessed in the study were p21 and PUMA.

As shown in Figure 3, p21 expression levels were not induced in both cancer cell lines after incubation with EPMC. However, PUMA expression levels in both cancer cell lines increased after treatment with EPMC (Figure 4). Nonparametric Kruskal-Wallis statistical analysis was used to test for significant differences in PUMA upregulation upon treatment with doxorubicin and EPMC. No significant difference in PUMA upregulation between doxorubicin and EPMC was found. This indicates that EPMC is a potent treatment candidate for cancer. Furthermore, from the graph obtained it showed that the increment was more pronounced in A549 (p53 wild-type). 
In a previous study, PUMA was reported to play an important role in benzyl isothiocyanate (BITC)-induced apoptosis. In the study, treatment with BITC clearly increased the level of PUMA in cells with wild-type p53 (MCF-7) (Anthony et al., 2012).

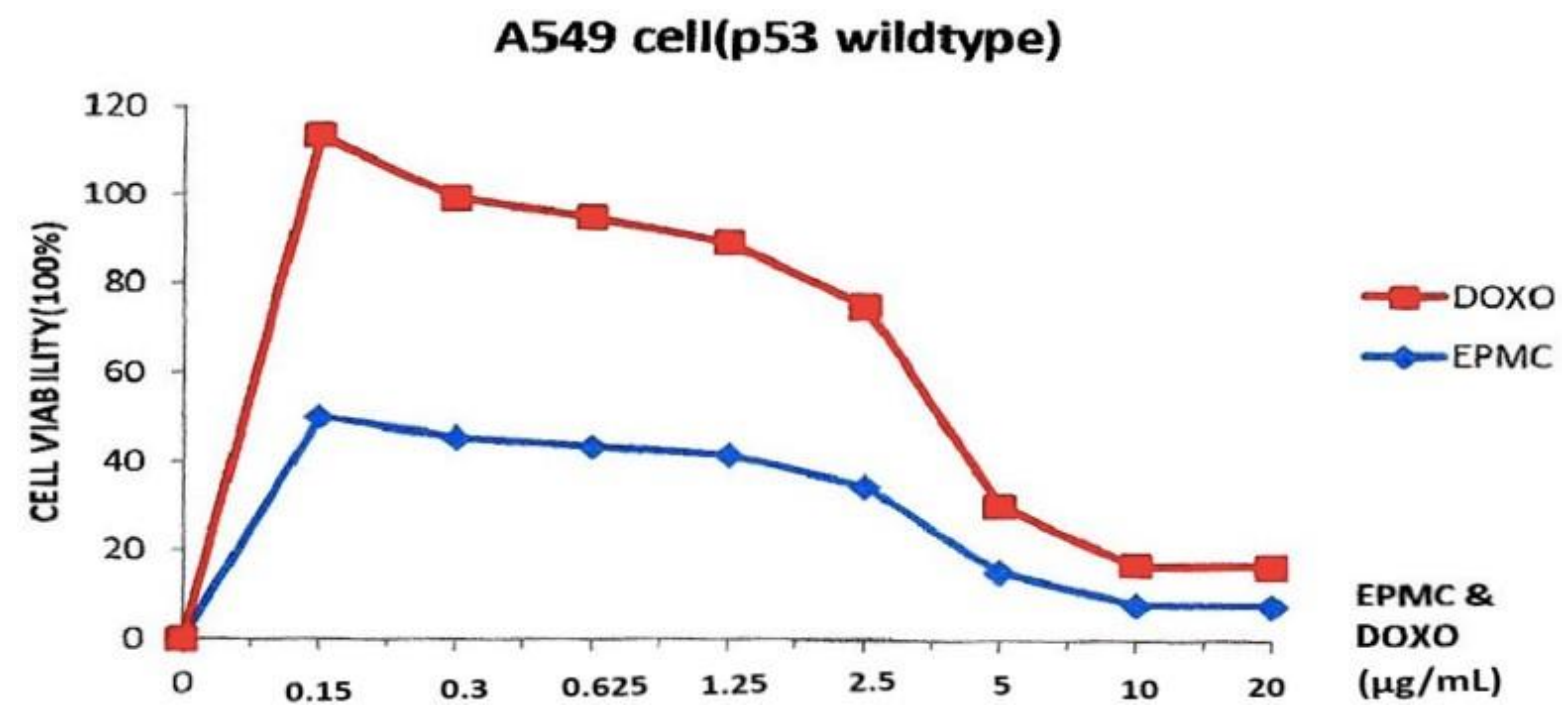

Figure 1. Ethyl-p-methoxycinnamate (EPMC) treatment schedules, EPMC dependent cytotoxicity and induced cell death in the presence of p53.

\section{H1299 cell (p53 null)}

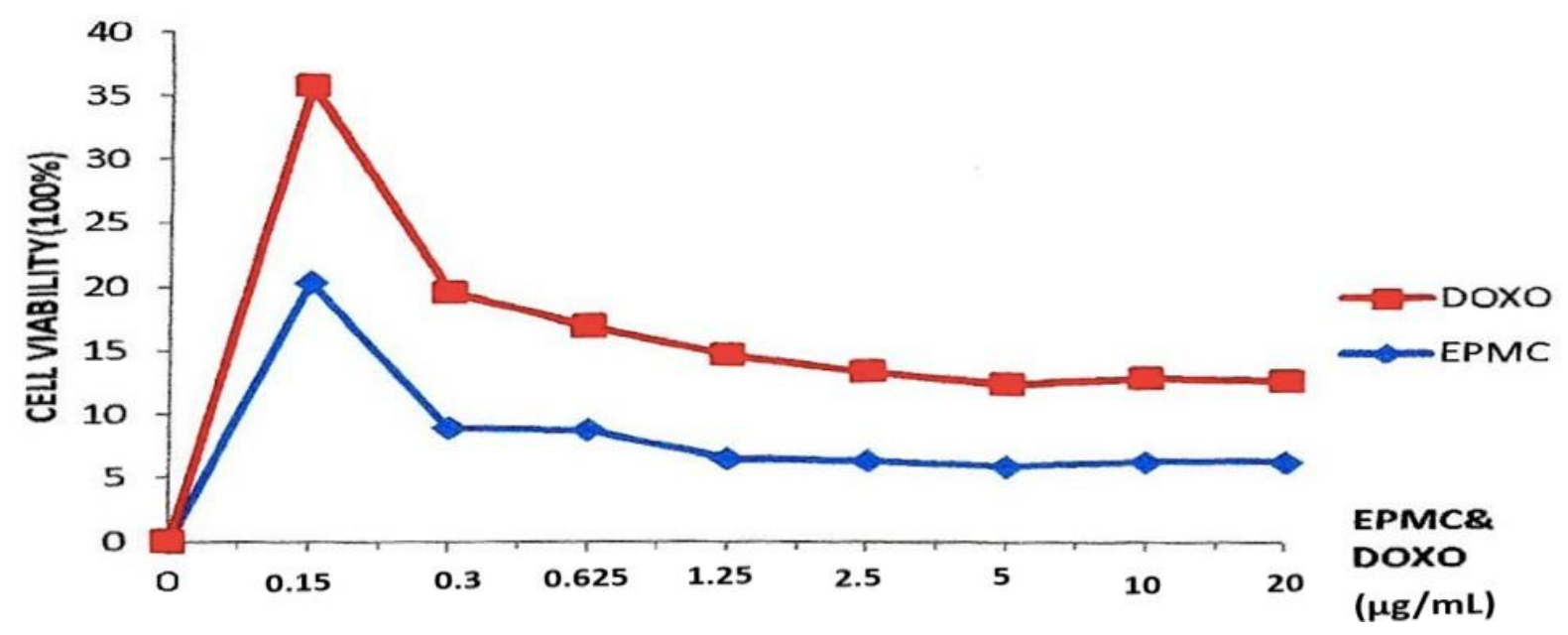

Figure 2. Ethyl-p-methoxycinnamate (EPMC) does not induce cytotoxicity and cell death in dose dependent manner in the absence of p53. 


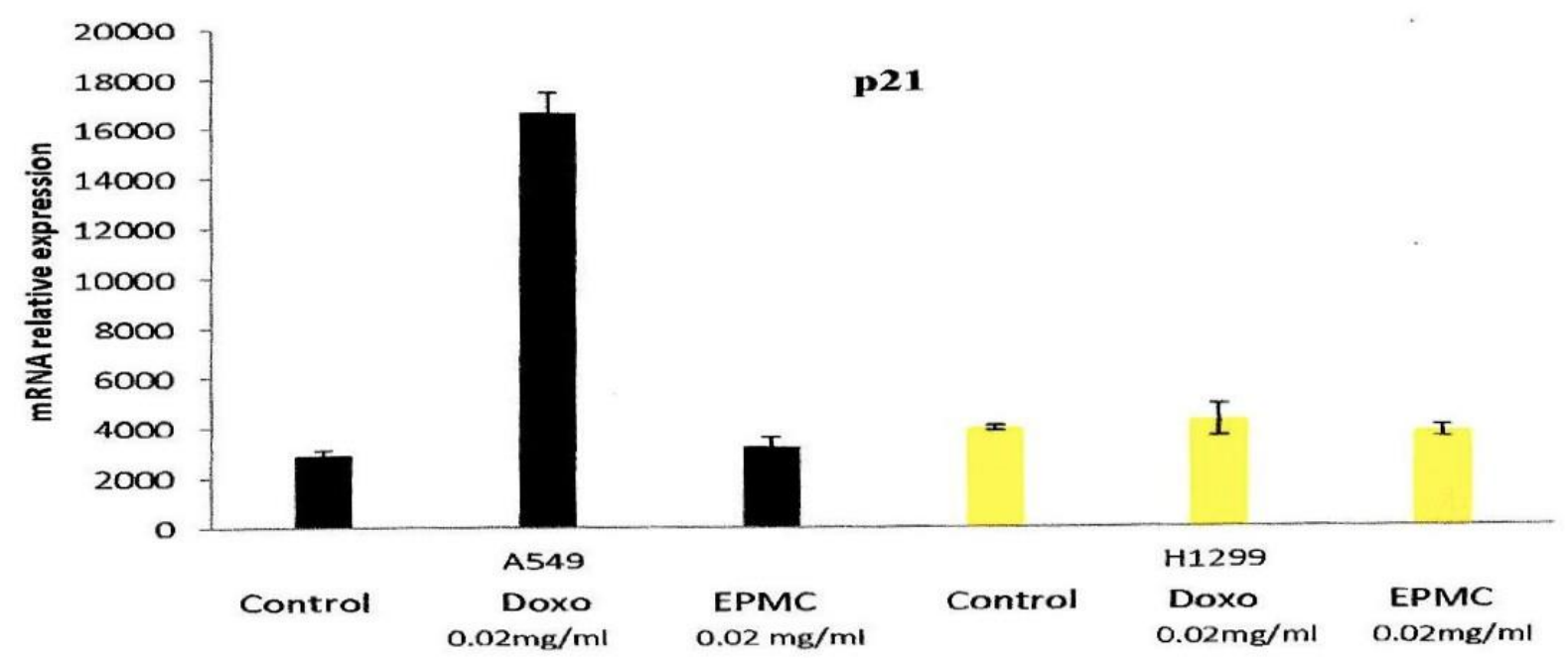

Figure 3. The graph shows that mRNA expression was not induced by EPMC incubation in both; A549 (p53 wild-type) and H1299 (p53 null) cancer cell line.

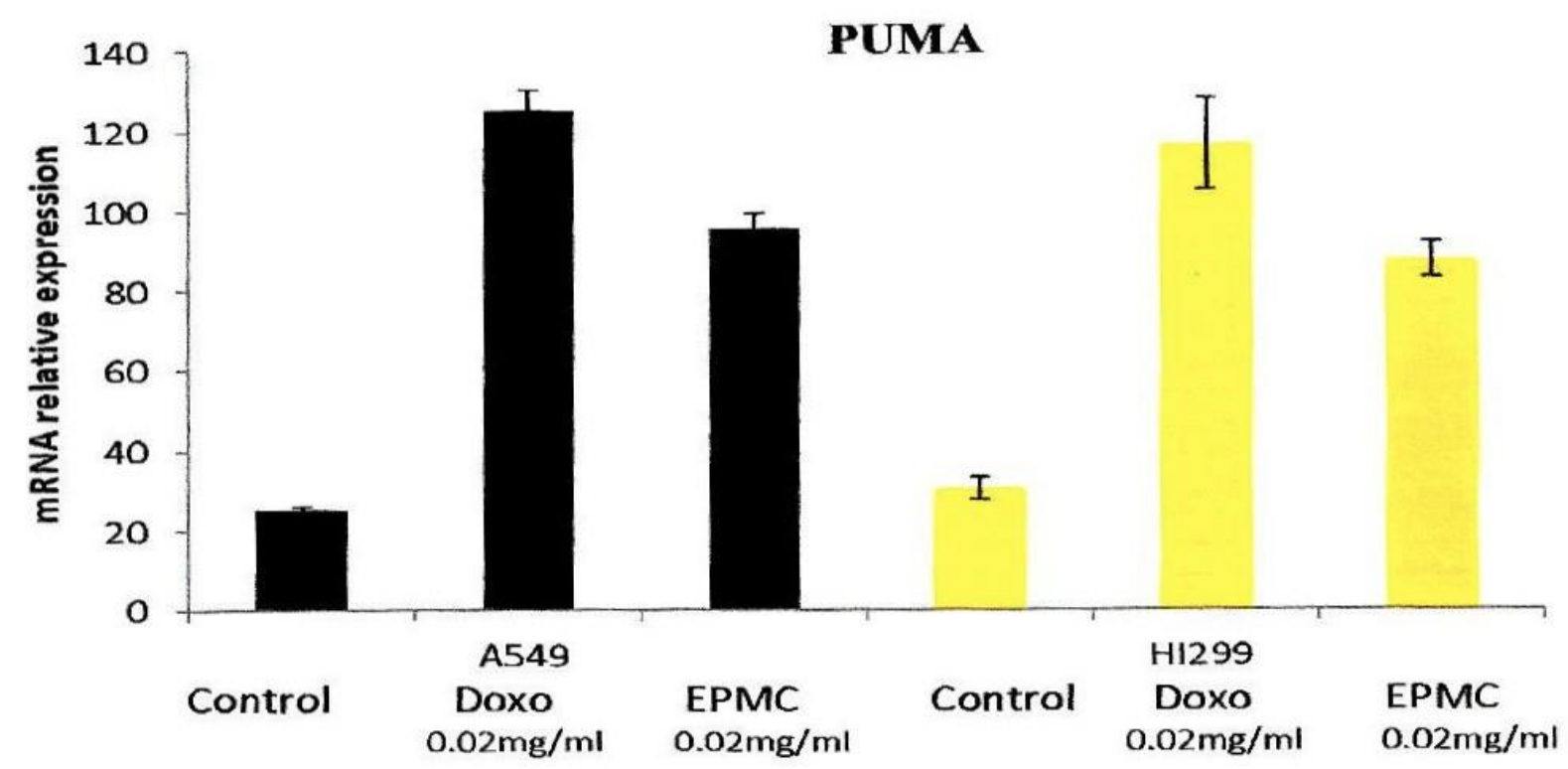

Figure 4. RT-PCR analysis revealed that mRNA expression levels were upregulated in both; A549 (p53 wild-type) and H1299 (p53 null) cancer cell line.

Nevertheless, the upregulation of PUMA mRNA expression does not indicate the involvement of the p53 pathway. This is because PUMA can also be activated independently and thus plays a role in p53-independent apoptosis as in the case of the p53 homolog p73, which is 
able to engage the PUMA promoter at the p53 response elements (Li et al., 2006).

Thus, in this study EPMC is shown to stimulate cytotoxic and apoptotic effects on human lung cancer cell lines. However, the apoptotic effect of EPMC does not involve the p53 pathway.

\section{Acknowledgement}

This research was partially supported by the grant program from the International Islamic University Malaysia, Research Endowment Fund Grant No.IIUM REFEDW B14-102-0987.

\section{References}

Amuamuta, A., Plengsuriyakarn, T., \& NaBangchang, K. (2017). Anticholangiocarcinoma activity and toxicity of the Kaempferia galanga Linn. Rhizome ethanolic extract. BMC Complementary and Alternative Medicine, 17(1), 213.

Antony, M. L., Kim, S. H., \& Singh, S. V. (2012). Critical role of p53 upregulated modulator of apoptosis in benzyl isothiocyanateinduced apoptotic cell death. PLoS One, 7(2).

Bai, L., \& Wang, S. (2014). Targeting apoptosis pathways for new cancer therapeutics. Annual Review of Medicine, 65, 139-155.

Beckerman, R., \& Prives, C. (2010). Transcriptional regulation by p53. Cold Spring Harbor Perspectives in Biology, 2(8), a000935.

Chiang, M. F., Chou, P. Y., Wang, W. J., Sze, C. I., \& Chang, N. S. (2013). Tumor suppressor WWOX and p53 alterations and drug resistance in glioblastomas. Frontiers in Oncology, 3, 43.

El-Deiry, W. S. (2003). The role of p53 in chemosensitivity and radiosensitivity. Oncogene, 22(47), 74867495.

Hientz, K., Mohr, A., Bhakta-Guha, D., \& Efferth, T. (2017). The role of p53 in cancer drug resistance and targeted chemotherapy. Oncotarget, 8(5), 8921.

Ichwan, S. J., Al-Ani, I. M., Bilal, H. G., Suriyah, W. H., Taher, M., \& Ikeda, M. A. (2014). Apoptotic activities of thymoquinone, an active ingredient of black seed (Nigella sativa), in cervical cancer cell lines. Chinese Journal of Physiology, 57(5), 249-255.

Ichwan, S. J., Husin, A., Suriyah, W. H., Lestari, W., Omar, M. N., \& Kasmuri, A. R. (2019). Anti-neoplastic potential of ethyl-pmethoxycinnamate of Kaempferia galanga on oral cancer cell lines. Materials Today: Proceedings, 16, 2115-2121.

Khoury, K., \& Domling, A. (2012). P53 mdm2 inhibitors. Current Pharmaceutical Design, 18(30), 4668-4678.

Klein, C., \& Vassilev, L. T. (2004). Targeting the p53-MDM2 interaction to treat cancer. British Journal of Cancer, 91(8), 1415-1419.

Li, J., Lee, B., \& Lee, A. S. (2006). Endoplasmic reticulum stress-induced apoptosis multiple pathways and activation of p53up-regulated modulator of apoptosis (puma) and noxa by p53. Journal of Biological Chemistry, 281(11), 7260-7270.

Omar, M. N., Hasali, N. H. M., \& Yarmo, M. A. (2016). Cytotoxicity Activity of Biotransformed ethyl p-methoxycinnamate by Aspergillus niger. Oriental Journal of Chemistry, 32(5), 2731-2734.

Omar, M. N., Rahman, S. A., Ichwan, S. J. A., Hasali, N. H. M., Rasid, F. A., \& Halim, F. A. (2017). Cytotoxicity effects of extracts and essential oil of Kaempferia galanga on cervical cancer C33A cell line. Oriental Journal of Chemistry, 33, 1659-1664.

Vogelstein, B., Lane, D., \& Levine, A. J. (2000). Surfing the p53 network. Nature, 408(6810), 307-310.

Wang, S., Zhao, Y., Bernard, D., Aguilar, A., \& Kumar, S. (2012). Targeting the MDM2p53 protein-protein interaction for new cancer therapeutics. In Protein-protein interactions (pp. 57-79). Springer, Berlin, Heidelberg.

Wang, Z., \& Sun, Y. (2010). Targeting p53 for novel anticancer therapy. Translational Oncology, 3(1), 1-12. 